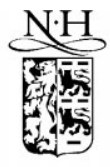

ELSEVIER

\title{
Speculation and the decision to abandon a fixed exchange rate regime
}

\author{
Ivan Pastine* \\ Bilkent University and CEPR, Department of Economics, Bilkent, 06533 Ankara, Turkey
}

Received 12 June 2000; received in revised form 2 January 2001; accepted 30 June 2001

\begin{abstract}
This paper demonstrates that the implications of first-generation speculative attack models do not hold if there is a rational, forward-looking policy maker. The policy maker will be able to avoid predictable speculative attacks by introducing uncertainty into the decisions of speculators. This changes the sudden attack into a prolonged period of increasing speculation and uncertainty. In addition, the model provides useful insights into the viability of temporary nominal anchor policies, and a theoretical foundation for a useful empirical methodology. (c) 2002 Elsevier Science B.V. All rights reserved.
\end{abstract}

Keywords: Speculative attacks; Nominal anchor; Optimizing BOP crises

JEL classification: F31; E58

\section{Introduction}

One of the central questions about speculative attacks on fixed exchange rate regimes is the degree to which they are predictable given information on the fundamentals of the economy. Much discussion centers around whether a particular crisis such as the breakdown in the European Monetary System (EMS) in 1992-1993, the Mexican peso in 1994, or the Thai baht in 1997, was the result of predictable deterioration of fundamentals or a sudden switch from one

*Tel.: + 90-312-290-1955.

E-mail address: pastine@bilkent.edu.tr (I. Pastine). 
equilibrium to another based on self-fulfilling expectations. The question is theoretically interesting, and of central practical importance. If most attacks are due to predictable movements in fundamentals (first-generation models) then fixed exchange rates may be attractive as long as the monetary authority is willing to subordinate its other goals to the exchange rate policy. On the other hand, if self-fulfilling expectations of crises (second generation models) are common then even if the monetary authority does everything right it may still not be able to avoid a speculative attack. Both types of attacks are supported by extensive theoretical literatures so economists have had to address the very difficult task of trying to differentiate these views empirically.

This paper reexamines the possibility of predictable speculative attacks. It argues that if monetary authorities are not myopic it is unlikely that predictable movements in fundamentals can create predictable speculative attacks. Once a rational, forward-looking policy maker is incorporated in these models very different, but equally interesting conclusions arise.

This literature grew from a framework developed by Krugman (1979) based on a mechanism by Salant and Henderson (1978). This framework posits a central bank with limited resources which is pursuing a fixed exchange rate policy but also has other, higher priority, policies that are fundamentally inconsistent with the exchange rate policy in the long run. Speculators are forward looking. They foresee the eventual abandonment of the fixed rate regime and the potential profit opportunities that might occur. As soon as profit opportunities begin to manifest themselves they attempt to exploit them by buying the central bank's foreign currency reserves in a sudden attack, forcing the early abandonment of the fixed exchange rate regime.

This structure is intuitive, elegant, and empirically tractable. Moreover, many countries which have experienced foreign exchange crises do indeed seem to have been pursuing other policies which appear to have been at odds with the fixed exchange rate system. Therefore the basic structure is quite attractive, and it has fared well empirically. It suffers, however, from an important shortcoming. In these models speculators are rational, forward-looking agents who are able to foresee the inevitable collapse of the fixed exchange rate regime, whereas the monetary authority is not. Even if we assume that the policy maker makes maintaining the fixed exchange rate regime a high priority, it would still realize

\footnotetext{
${ }^{1}$ 'First generation' and 'second generation' refer to Flood and Marion's (1999) useful taxonomy of speculative attack models. First generation models place emphasis on speculative attacks driven by predictable movements in fundamentals while second generation models place emphasis on speculative attacks that arise due to multiple equilibria. The predictable attack literature was started by Krugman (1979) and Salant and Henderson (1978). The multiple equilibria explanation of speculative attacks is due to Flood and Garber (1984a) in the natural resource context, and Obstfeld (1986) in the fixed exchange rate context. Surveys of this extensive literature are given by Agénor et al. (1992), Blackburn and Sola (1993), and Flood and Marion (1999). For an elegant example of an approach to differentiating these views empirically see Jeanne (1997).
} 
that indefinite maintenance is impossible given its other objectives. It would therefore take steps to minimize the costs associated with the inevitable collapse of the fixed exchange rate system.

It is not clear that the results of these models are robust to the inclusion of an optimizing policy maker. If the structure is extended to allow for a forwardlooking, rational policy maker then strategic interaction between speculators and the monetary authority becomes critical to the analysis. Since the policy maker would foresee the speculative attack, it would be tempted to abandon the fixed exchange rate just before the crisis, thereby avoiding large reserve losses. However, if it was optimal for the policy maker to do so, rational speculators would take this into account and change their strategies, potentially altering the date or nature of the attack. I examine this issue, analyzing strategic interaction between speculators and an optimizing policy maker in a linear version of the Krugman model developed by Flood and Garber (1984b). There are five reasons why it may be useful to do so.

\subsection{Theoretical considerations}

Firstly, it is useful to include a rational, forward-looking policy maker on purely theoretical grounds. The most widely used, most often cited, and most empirically tractable class of speculative attack models do not tell a complete story. The driving force of these models is sophisticated, forward-looking behavior on the part of speculators, and completely myopic behavior on the part of the central bank. Therefore it is important to examine whether the general conclusions of this class of models are robust to a more realistic specification of central bank behavior.

Obviously this is not the first paper to examine the issue of optimizing policy makers in speculative attack models. In the context of second generation models, work by Cole and Kehoe (1996a,b), Davies and Vines (1995), Obstfeld (1994, 1996), Ozkan and Sutherland (1998) and Velasco (1997) show that speculative attacks based on multiple equilibria are consistent with optimizing behavior of the monetary authorities, and examine the channels through which such attacks may occur. In the context of first generation models, papers by Andersen (1994), Morris and Shin (1998), and Ozkan and Sutherland (1994, 1995) examine strategic interaction between speculators and optimizing monetary authorities.

What is new in this paper is not the inclusion of an optimizing policy maker, but rather the explicit examination of the predictability of speculative attacks in the presence of an optimizing policy maker. The existing literature either focuses on self-fulfilling expectations of attacks, or construct models in which the issue does not arise. In Andersen (1994) and Morris and Shin (1998) there is no element of

\footnotetext{
${ }^{2}$ This paper straddles the line between first and second generation models, examining the relationship between predictable speculative attacks and multiple equilibria.
} 
predictability in the economy so the issue of attack predictability does not arise. Ozkan and Sutherland (1994, 1995) examine the behavior of optimizing central banks in models where the central bank cares about speculation through its influence on the interest rate, but it does not find attacks themselves detrimental. Thus, at the margin, the central bank is comparing the losses associated with an infinitely short decrease in the duration of the fixed exchange rate regime with the losses associated with high interest rates for an infinitely short period of time during a speculative attack.

These models capture an important element of reality, and their implications are interesting and relevant. However, these models do not examine the predictability of speculative attacks. In reality policy makers also have a strong aversion to speculative attacks themselves. Attacks have significant and long-lasting political and economic consequences that go far beyond momentary increases in interest rates. In order to examine whether speculative attacks can be predictable based on predictable movements in fundamentals it is necessary to construct a model in which movements in fundamentals are predictable and in which a speculative attack results in significant losses to the policy maker.

This paper constructs an optimizing version of a standard, and widely used model of predictable speculative attacks. The policy maker is rational and has an objective function which gives it an incentive to avoid sudden speculative attacks, if possible. It is shown that when the policy maker dislikes speculative attacks a very different type of strategic interaction arises. The policy maker and speculators find themselves in a preemption game. ${ }^{3}$ The policy maker would like to abandon the fixed exchange rate regime just before a speculative attack. But speculators would like to predict this preemptive abandonment and exploit it through their foreign currency purchases.

Typically preemption games admit both pure-strategy and mixed-strategy equilibria. In the fixed exchange rate context, however, pure-strategy equilibria do not exist. The difference arises because in many industrial organization applications moving at the same time is detrimental to both sides, while in the fixed exchange rate context speculators are willing to buy foreign currency at the same time that the policy maker abandons the fixed exchange rate regime, but not earlier. As a basic game form, the closest analogy to this paper is work by Bénabou (1989) who examines optimal pricing strategy for a monopolist in an inflationary environment facing consumers who are able to store the good for one period. He shows that the monopolist will generally pursue a mixed strategy in order to reduce consumer hoarding before price increases. The monopolist's problem is very close to the problem of recurring devaluations in a fixed exchange

\footnotetext{
${ }^{3}$ Preemption games are the rough converse of wars of attrition. In a war of attrition each player would like to be the last to move. In a preemption game each player would like to be the first to move. A classic example of a preemption game is the problem of two firms, each deciding whether to open a store in a location where demand cannot support both operations.
} 
rate system, ${ }^{4}$ and Pastine (2000) shows that Bénabou's analysis extends to the fixed exchange rate context. Whenever devaluations are large enough so that successful speculation is profitable, the monetary authority must play a mixed strategy.

Here in the context of a first-generation speculative attack model, similar strategic interaction arises. This paper analyzes the subgame-perfect Nash equilibria in a game between speculators and a rational forward-looking policy maker. Rather than simply choosing a critical level of fundamentals to abandon the fixed exchange rate regime and accepting a speculative attack, the policy maker will play a mixed strategy - deliberately introducing uncertainty into the decisions of speculators. By making it difficult for speculators to predict when it will change the exchange rate policy, the policy maker can hope to avoid a speculative attack.

This incentive to introduce uncertainty into the decisions of speculators has significant implications for our understanding of the period leading up to changes in exchange rate policy. It implies that the uncertainty associated with these policy changes may not be an exogenous feature of fixed exchange rates, but may be introduced endogenously, and deliberately by the monetary authorities in an attempt to avoid speculative attacks. Note, however, that one of the main arguments in favor of fixed exchange rates is that they may decrease the exchange rate uncertainty inherent in a floating rate system. The results of this paper suggest that, in practice, the incentives of the monetary authorities may lead them to deliberately reintroduce much of this uncertainty in an attempt to avoid speculative attacks.

\subsection{Explaining observed behavior}

Secondly, the inclusion of an optimizing monetary authority leads to theoretical results which are closer to observed behavior. Typically breakdowns of fixed exchange rate regimes are preceded by increasing interest differentials, and increasing forward exchange rate premia. The breakdowns are accompanied by large depreciations of the domestic currency. None of these features are present in non-stochastic versions of these models. They can be generated in stochastic versions but then the length of the period of increasing interest rates and forward exchange rate premia is directly related to the size of the expected shocks. Moreover, interest differentials and forward rate premia must be less than they would be in a floating exchange rate regime. Additionally, in the traditional models the size of a jump in the exchange rate is directly related to the size of the

\footnotetext{
${ }^{4}$ It is so close in fact that Bénabou devotes the last paragraph of his paper outlining the intuition for why the monetary authority must play a mixed strategy when altering a fixed exchange rate. Flood and Marion (1999) also suggest that mixed-strategy equilibria may arise in similar circumstances.

${ }^{5}$ Both Nash equilibrium and subgame perfection are implicit in the standard analysis of firstgeneration speculative attack models.
} 
last shock. In fact the magnitude of the jump must be less than the jump that would occur if the same shock hit in a flexible exchange rate environment. So, while these models are consistent with observed behavior, it seems unlikely that the ubiquitous and dramatic depreciations which accompany fixed exchange rate abandonments are all driven by large exogenous shocks.

However, when we include an optimizing policy maker, the incentive to introduce uncertainty into the decisions of speculators implies that these empirically observed phenomena (increasing interest rates, forward exchange rate premia, and large jumps in the exchange rate after the collapse of the fixed rate) arise in equilibrium even in a completely non-stochastic framework. Therefore, it is no longer necessary to argue that exogenous shocks are large in order to explain observed fixed exchange rate abandonments using this class of model. It should be noted that these empirical implications, as well as those in Section 1.3, apply to abandonments which are not preceded by speculative attacks. The implications for abandonments which are preceded by speculative attacks are discussed in Section 1.5 .

\subsection{A foundation for an empirical methodology}

The third useful implication of introducing a non-myopic policy maker is that it helps provide a theoretical foundation for a useful empirical methodology. Cumby and van Wijnbergen (1989) develop an elegant method of estimating the evolution of a crisis when agents do not perfectly foresee the collapse. They capture the idea that changing the exchange rate regime is a policy decision by making the assumption that the conditional p.d.f. of the level of reserves at the time of abandonment is distributed uniformly. This specification permits a very rich stochastic structure and has been quite successful empirically. However, the ad hoc nature of the specification has made the approach unattractive to many practitioners.

In this paper, the inclusion of an optimizing policy maker allows for the explicit derivation of the probability of abandoning the fixed exchange rate regime in each state. This derived expression for the probability of abandoning the fixed exchange rate is remarkably similar to that assumed by Cumby and van Wijnbergen. Hence it is possible to think of this paper as a theoretical foundation for their earlier empirical work, or, conversely, their empirical work as an ex ante empirical application of this type of model.

\subsection{Are temporary nominal anchor policies viable?}

The fourth reason why it may be useful to incorporate an optimizing policy maker in a model of fixed exchange rate abandonment is that it provides insight into the viability of nominal anchor policies. It is often suggested that a temporary fixed exchange rate policy can be useful in providing a 'nominal anchor' to help 
stop runaway, expectations-driven inflation. The idea is that by making a highlyvisible commitment to maintaining one nominal price the monetary authority can encourage rapid adjustment of expectations, and hence control inflation quickly.

Of course, fixed exchange rate policies in highly inflationary environments are inherently dangerous. The risk of a speculative attack is always present. If the policy works, however, it would only need to be in place for a short time. As soon as inflation expectations adjust it should be possible to abandon the fixed exchange rate policy. Unfortunately, if the policy maker is planning to abandon the fixed exchange rate regime, speculators would attempt to exploit this through their foreign currency purchases. Therefore, it is not clear that a smooth transition out of a temporary nominal anchor policy is consistent with rational expectations on the part of speculators. While these policies are often recommended for high inflation countries, no theoretical work has been done to investigate these difficulties involved in ending a fixed exchange rate policy gracefully.

By introducing a rational optimizing policy maker into the Krugman model of speculative attacks, one can analyze this issue in a consistent manner. The results suggest that it may, in fact, be possible for central banks to extricate themselves from fixed exchange rate regimes without speculative attacks, but it will be a chancy undertaking. The line between success and failure will be very fine indeed. These results closely match the 1998-1999 Brazilian experience where there was a protracted period of serious concern that deteriorating fundamentals would precipitate a speculative attack. In the end, while there was considerable speculative pressure, an attack did not occur and the central bank was able to abandon the fixed exchange rate regime relatively gracefully. The results of the model shed some light on why Brazil was able to avoid an attack while many other countries have not been so fortunate.

\subsection{Are predictable attacks possible?}

Lastly, the inclusion of an optimizing policy maker in this framework permits insights into the nature of speculative attacks themselves. There are any number of possible definitions of a speculative attack that one could use depending on the empirical observations that one is trying to explain. Here I will follow Krugman in taking the phenomenon to be explained to be an event where,

... generally well before the gradual depletion of reserves would have exhausted them, there is a sudden speculative attack that rapidly eliminates the last of the reserves. The government then becomes unable to defend the exchange rate any longer. Krugman (1979, pp. 311-312).

Thus for the purposes of this paper, a speculative attack will be taken to be a sudden, large drop in central bank foreign currency reserves. This will be contrasted with an extended period of speculation which gradually puts increasing 
pressure on the monetary authorities (a 'speculative siege' if we want to maintain the martial terminology).

It is shown that with a rational forward-looking policy maker speculative attacks based on predictable movements in fundamentals are not possible. By introducing uncertainty into the decisions of speculators, a rational policy maker can avoid a predictable speculative attack turning it into an extended period of gradually increasing speculative pressure. ${ }^{6}$ This is true even when the policy maker has only a single policy instrument available to avoid speculative attacks. The branch of the speculative attack literature that places its emphasis on predictable movements in fundamentals cannot generate speculative attacks when we allow for a rational forward-looking policy maker. This suggests that any observed speculative attacks must be due to multiple equilibria, unpredictable jumps in fundamentals, or non-rational policy makers.

Of course the difference between a sudden attack and a protracted siege is in the eye of the beholder. The results suggest that for an observed event to be generated by a predictable deterioration in fundamentals (a first-generation attack), it must be the case that the policy maker expected that the event would evolve gradually enough so that it was worth enduring it in order to gain the benefit of having the fixed exchange rate during the event itself. Thus the intense speculative pressure on the Brazilian central bank in 1998-1999 which evolved over a period of months may well be explained by first-generation speculative attack models. It is at least plausible that the Brazilian central bank was willing to endure this speculation in order to gain the benefit of 4-6 months of fixed exchange rates. However, the attacks that occurred in Sweden 1992, Turkey 1994 and 2001, Mexico 1994, and Thailand 1997 evolved much more quickly. For example, in order to use first-generation models to explain the 1-day Swedish attack on November 19, 1992 the results of this paper suggest that the Swedish central bank

\footnotetext{
${ }^{6}$ It is interesting to note while the seminal Salant and Henderson (1978) paper is justly famous for starting the speculative attack literature, in the paper itself speculative attacks are but a special case of a more general theory. The emphasis in the paper is on gradual but inexorable speculative pressure in response to government policy.

${ }^{7}$ This last possibility is not as far fetched as it may first appear. Here I am following Mas-Colell, Whinston and Green (1995, Definition 1.B.1) in defining rationality to include preference transitivity. However, group decision making will often suffer from the Condorcet paradox, where groups which do not have a dictator will behave as if they have non-transitive preferences even though the preferences of every individual in the group are transitive. Work by Velasco (1994) finds that speculative attacks may be generated through non-cooperative competition between different branches of government. It is also possible, at least potentially, that they may arise through a non-strategic, but non-dictatorial decision making process of a single branch of government.

${ }^{8}$ It should be noted that events such as this are difficult to explain with second-generation models. They are possible in such models if the probability of a switch between equilibria is gradually increasing over an extended period. But since these models do not make any predictions on how the probability of a switch between equilibria is likely to evolve, such events are not predicted by the theory.
} 
must have liked fixed exchange rates so much that it was willing to deliberately accept the attack just to extend the fixed exchange rate by that 1 day. Certainly this is theoretically possible, but it does not seem plausible.

In addition, the results of this paper may also have implications for what types of events can trigger an attack. In the multiple-equilibria explanation for speculative attacks it has been difficult to pin down what events might trigger a switch between equilibria. While this paper does not solve this problem, it does offer intuition about what types of events cannot trigger an attack. In equilibrium even with only a single policy instrument, a forward-looking policy maker can avoid predictable speculative attacks, albeit at considerable cost. This suggests that the timing of speculative attacks must be unpredictable. Hence, with multiple equilibria, the mechanism used by speculators to coordinate their expectations on the attack equilibrium must be based on non-predictable variables.

The starting point for this paper is a widely used version of the Krugman (1979) model of speculative attacks on fixed exchange rates. The goal here is not to provide a realistic description of an attack episode. Rather the aim is to develop a clear understanding of the strategic interaction between speculators and a monetary authority which wishes to avoid speculative attacks. To this end a very simple and transparent version of the model is chosen in order to make the mechanism at work as clear as possible. The reader should be aware, however, that this stylized structure has been greatly extended by many authors, so a large number of more realistic and detailed models of speculative attacks use essentially the same mechanism. The standard model is developed in some detail in Section 2. Then, in Section 3 , it is expanded to include an explicitly optimizing policy maker. The paper is concluded in Section 4, where the implications for our understanding of the breakdown of fixed exchange rates are discussed.

\section{The model with a myopic policy maker}

Before introducing the policy maker's optimization problem, it is useful to consider the problem as it is usually presented, with fully rational speculators and a myopic policy maker. This framework posits a central bank with limited reserves which is pursuing a fixed exchange rate policy but also has other, higher priority, policies which are fundamentally inconsistent with the exchange rate policy in the long run.

\subsection{The model}

The model used here is a non-stochastic version of a path-breaking model by Flood and Garber (1984b). It is a single good, small open economy model in which purchasing power parity implies that, 


$$
P_{t}=S_{t} P_{t}^{*}
$$

at all times $t$, where $S_{t}$ is the domestic currency price of foreign currency, $P_{t}$ is the domestic price level, and $P_{t}^{*}$ is the foreign currency price of output which is assumed constant and normalized to 1 . Uncovered interest parity is assumed to hold in each period,

$$
i_{t}=i^{*}+E_{t}\left[\left(S_{t+1} / S_{t}\right)-1\right]
$$

where $i_{t}$ is the nominal interest rate on domestic securities and $i^{*}$ is the nominal interest rate on foreign securities, which is assumed to be constant. Money demand is given by,

$$
M_{t}^{d} / P_{t}=\alpha-\beta i_{t} .
$$

It is assumed that money demand is positive when the domestic interest rate is equal to the world rate, $\left(\alpha-\beta i^{*}\right)>0$. The money supply consists of the book value of central bank foreign currency reserves $R_{t}$ and domestic credit $D_{t}{ }^{9}$,

$$
M_{t}^{s}=R_{t}+D_{t}
$$

and the evolution of domestic credit follows the exogenous process,

$$
D_{t}=D_{t-1}+\mu
$$

where $\mu$ is a positive constant. In this model the parameter $\mu$ represents the other higher priority policies of the central bank which are inconsistent with the fixed exchange rate policy in the long run. $\mu$ is usually interpreted as a need to monetize a fiscal deficit.

This specification implies that foreign currency sales are unsterilized, which is quite unrealistic. Flood, Garber and Kramer (1996) show how this model can be extended to incorporate sterilized foreign currency transactions. Their technique is equally applicable to the optimizing version of the model presented in the next section. However, in order to make the mechanism at work as clear as possible, here we will take the simpler, if less realistic, assumption of unsterilized transactions.

In this myopic case, as long as its reserves are above a critical level $\bar{R}$ the central bank pursues a fixed exchange rate policy, buying and selling foreign currency on demand, at the exchange rate $\bar{S}$. Once its reserves fall to $\bar{R}$ the central

\footnotetext{
${ }^{9}$ This is the money supply specification which is standard in the speculative attack literature. In this context if the money supply is set to $\bar{R}+D_{t}$ during the floating exchange rate period, this specification is equivalent to a specification in differences $M_{t}^{s}-M_{t-1}^{s}=S_{t}\left(r_{t}-r_{t-1}\right)+\left(D_{t}-D_{t-1}\right)$ where $r_{t}$ is central bank holdings of foreign currency denominated in foreign currency. This is because in the fixed exchange rate period the exchange rate is constant, and in the floating rate period foreign currency reserves are constant. To facilitate direct comparison with the existing literature this standard and innocuous short cut will be used.
} 
bank must leave the foreign exchange market forever and the exchange rate will float freely. The assumption of limited reserves has received considerable criticism since it implies a limit to the ability of countries to borrow. This criticism is particularly relevant to the breakdown in the EMS, since the European countries abandoned the exchange rate mechanism long before their borrowing capacities were exhausted. One of the interesting implications that will emerge from the analysis here is that with an optimizing monetary authority the fixed exchange rate mechanism will usually be abandoned before reserves fall to their lower limit. With an optimizing policy maker reserves can be substantially above $\bar{R}$ at the time of the move to a floating exchange rate system. However, for now consider the traditional case where the central bank abandons the fixed exchange rate system if, and only if, reserves fall to $\bar{R}^{10}$

\subsection{Timing}

There are at least three reasonable specifications of the timing in this market which could be adopted. The speculators could choose their levels of speculative balances first followed by the policy maker's move, the policy maker could move first followed by speculators, or the players could make their decisions simultaneously. The choice between these specifications is essentially arbitrary. Fortunately it is also innocuous. The results of the model, both traditional myopic policy maker version and the optimizing extension that will be presented in the next section, are unchanged except for minor notational differences by the choice of timing. To fix ideas we will adopt the fairly standard timing specification of speculators moving first followed by the policy maker. But the results from other timing specifications are the same.

\subsection{Equilibrium}

Suppose that speculators expected that the central bank would never abandon the fixed exchange rate regime, $E_{t}\left[S_{t+1}\right]=\bar{S}$ for all $t$. In that case from Eqs. (1)-(4),

$$
R_{t}+D_{t}=\left(\alpha-\beta i^{*}\right) \bar{S}
$$

since (2) would imply that $i_{t}=i^{*}$ at all times. Domestic credit is increasing over

\footnotetext{
${ }^{10}$ The traditional assumption of the exogeneity of the critical reserve level has also received criticism. Flood and Marion (1999) argue that the central bank's commitment to the fixed exchange rate regime is likely to be dependent on the state of the economy. They suggest that this may be incorporated into the model by making the critical level of reserves $\bar{R}$ a function of the state of the economy.
} 
time so reserves must be decreasing and the fixed exchange rate will be abandoned at the state $\tilde{T}$ defined by,

$$
D_{\tilde{T}}=\left(\alpha-\beta i^{*}\right) \bar{S}-\bar{R} .
$$

Therefore it is not rational for speculators to believe that the fixed exchange rate will be maintained indefinitely. Hence, to solve the speculators' optimization problem, it is necessary to determine the exchange rate that will prevail after the fixed rate regime is abandoned.

Define the shadow floating exchange rate, $\tilde{S}_{t}$, as the exchange rate that would prevail if the exchange rate were floating at $t$. In order for the exchange rate to be floating, it must be that reserves fell to $\bar{R}$ at one point, and after that point all foreign currency transactions will take place in private markets so the money supply will simply be $\bar{R}+D_{t}$. Eqs. (1)-(5) would yield,

$$
\left[\left(\alpha-\beta i^{*}\right)+\beta\right] \tilde{S_{t}}=\left[\bar{R}+D_{t}\right]+\beta E_{t}\left[\tilde{S}_{t+1}\right] .
$$

Assuming no speculative bubbles in the floating rate period, this difference equation implies that,

$$
\tilde{S}_{t}=\frac{\bar{R}+D_{t}}{\left(\alpha-\beta i^{*}\right)}+\frac{\beta \mu}{\left(\alpha-\beta i^{*}\right)^{2}} .
$$

If the shadow floating exchange rate is less than the fixed exchange rate then there is clearly no incentive for speculators to engage in a speculative attack. An attack would cause a breakdown of the exchange rate regime and speculators would make a loss. Therefore no individual speculator would hold foreign currency during an attack, and so an attack cannot occur. Speculators will therefore wait until the post-attack exchange rate equals the fixed rate. At that point if the breakdown is delayed there will be profits to be made by speculating in foreign currency. In this model, competition for speculative profits ensures that a speculative attack occurs the instant they become available. Therefore the attack must occur at the state where $\tilde{S}_{t}=\bar{S}$ so that there is no instantaneous jump in the exchange rate. ${ }^{11}$

Defining $\bar{T}$ as the date of the speculative attack in this traditional version of the model $\tilde{S}_{\bar{T}}=\bar{S}$ yields,

$$
D_{\bar{T}}=\left(\alpha-\beta i^{*}\right) \bar{S}-\bar{R}-\left[\beta \mu /\left(\alpha-\beta i^{*}\right)\right] .
$$

\footnotetext{
${ }^{11}$ Obstfeld (1986) shows that this is, in fact, the only possible 'market-clearing' equilibrium in the model. If the analysis is expanded to include the full range of subgame-perfect Nash equilibria (allowing for the possibility of shortages of foreign currency during a speculative attack) additional equilibria can emerge, see Pastine (1996). However, to facilitate comparison with the bulk of the existing literature, these equilibria are suppressed here and attention is focused solely on marketclearing equilibria.
} 


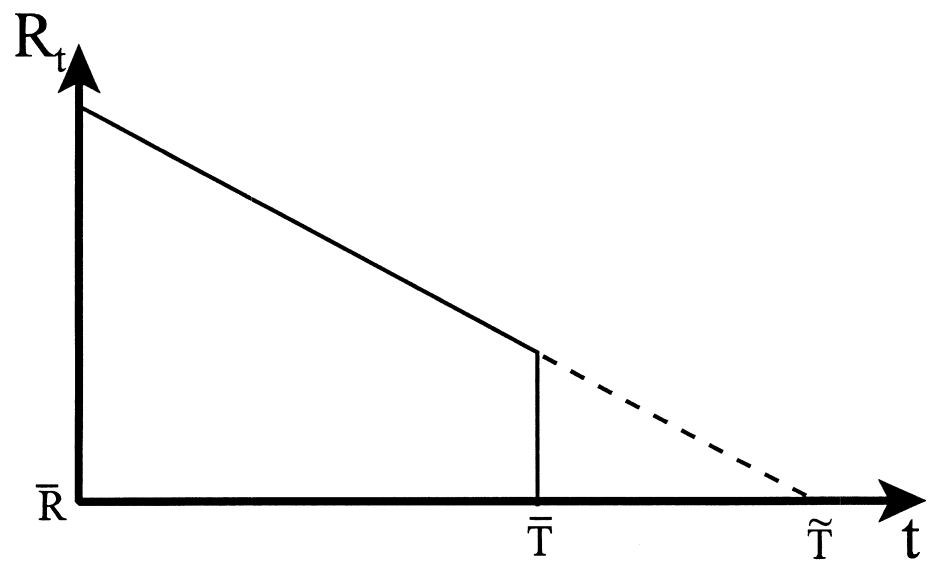

Fig. 1. Reserves with a myopic policy maker.

Together with Eqs. (7) and (5) this means that $\tilde{T}-\bar{T}=\beta /\left(\alpha-\beta i^{*}\right)$, implying that the speculative attack will cause the collapse of the fixed exchange rate before it would otherwise be abandoned. Fig. 1 shows the path of reserves. Initially reserves follow (6), declining one-for-one with the expansion of domestic credit. At $\bar{T}$, however, the shadow floating exchange rate rises to the fixed rate and the remaining $\mu \beta /\left(\alpha-\beta i^{*}\right)$ reserves are purchased in a sudden speculative attack which forces the abandonment of the fixed rate regime.

\section{An optimizing policy maker}

An important shortcoming of this traditional version of the model is that forward-looking private agents are anticipating the breakdown of the fixed exchange rate regime but the policy maker is not. The speculative attack results in a sudden drop in foreign currency reserves at $\bar{T}$. If this is undesirable it can be easily avoided by simply abandoning the fixed rate at time $\bar{T}-1$. A rational policy maker should realize that the move to a floating rate system is inevitable. The only open issue is how painful that move will be and whether there are any alternative strategies which might make it somewhat less costly.

\subsection{The policy maker's problem}

To analyze this issue, an objective function for the policy maker is required. There are any number of such objective functions available and any choice is necessarily imperfect. The central results of this paper require that the objective function have two features. Firstly, the policy maker must dislike speculative 
attacks, with the degree of distaste being continuous in the size of the attack. Secondly, in the absence of an attack, the policy maker must prefer to maintain the fixed exchange rate.

In the proceeding analysis the focus will be on how the existence of an optimizing policy maker changes the speculators' problem. Hence, it is convenient to have the objective function depend directly on speculators' choice variable. In this stylized model movements in reserves can be used as a proxy for the real costs of speculative attacks that are present in more realistic models. It is therefore assumed that the policy maker prefers more reserves to less, and fixed exchange rates to floating exchange rates. The first assumption will imply that speculative attacks are undesirable for the policy maker. The second assumption makes it possible to rationalize the initial existence of the fixed exchange rate regime. ${ }^{12}$ Formally, at the end of each period $t$, the policy maker will receive a payoff of $R_{t}$ if the exchange rate is fixed, and $R_{t}-\Gamma$ if the exchange rate is floating, ${ }^{13}$ where $\Gamma>0$. The future is discounted at the rate $\delta \in(0,1)$.

When the fixed rate is abandoned, all foreign currency transactions take place in private markets so policy maker's per period payoff in each period will be $R_{t}-\Gamma$ if the exchange rate is abandoned in $t$. Hence, if the fixed rate is abandoned then the expected present value of the policy maker's objective function is given by $\left(R_{t}-\Gamma\right) /(1-\delta)$. However, if the fixed exchange rate is not abandoned, future foreign currency transactions will take place with the central bank. Therefore the expected payoff from this strategy depends on what the policy maker expects will happen in the future. The expected present value of the policy maker's objective function is the maximum of the value if it abandons the fixed exchange rate, or the value of the game if it does not

$$
V_{t}=\max \left\{\left[\frac{R_{t}-\Gamma}{1-\delta}\right],\left[R_{t}+\delta E_{t}\left(V_{t+1}\right)\right]\right\} .
$$

This maximization problem is subject to the constraint that if reserves fall to $\bar{R}$ the central bank must switch to floating exchange rates. The policy maker compares the benefit from abandoning the fixed exchange rate system with the current and expected future value of maintaining it.

This specification implies that if the policy maker is expecting a speculative attack, it will find it optimal to abandon the fixed exchange rate regime in the period before the attack. That is, if in the coming period the expected drop in

\footnotetext{
${ }^{12}$ Andersen (1994) presents an elegant model endogenizing central bank preferences for fixed exchange rates in a related context.

${ }^{13}$ Note that $R_{t}$ is the book value of reserves, and (1) implies that the price level is equal to the exchange rate. Thus, in the fixed rate period the real value of central bank reserves is equal to $R_{t} / \bar{S}$. In the flexible exchange rate period all foreign currency transactions take place in private markets, so the real value of reserves does not change. Therefore, the policy maker's one period payoff is just the real value of reserves, normalized for algebraic convenience (and minus a constant if the exchange rate is floating).
} 
reserves is large, the policy maker will move to a floating exchange rate regime to avoid the attack. For given expectations of future reserves, a higher value of $R_{t}$ implies a larger expected drop in reserves. Notice that $E_{t}\left(V_{t+1}\right)$ includes information on the expected level of future reserves. Therefore, for a given value of $V_{t+1}$, high current period reserves make abandoning the fixed exchange rate system more attractive. There is simply more to lose by waiting.

Since the policy maker is pursuing a fixed exchange rate policy, it must find it optimal to do so. This places a lower bound on the value of the parameter $\Gamma$, the policy maker's preference for fixed exchange rates. To derive this lower bound notice that the opportunity cost of waiting one period to abandon the fixed exchange rate is given by the value of abandoning in period $t$ minus the discounted value of abandoning in period $t+1$,

$$
\left(\frac{R_{t}-\Gamma}{1-\delta}\right)-\delta\left(\frac{R_{t+1}-\Gamma}{1-\delta}\right)
$$

For the choice of a fixed exchange rate to have ever been optimal, this opportunity cost must be less than the benefit of waiting when there is no speculative attack, $R_{t}$. This reduces to

$$
\delta\left(R_{t}-R_{t+1}\right)<(1-\delta) \Gamma .
$$

When there is no speculative attack, reserves are given by (6). From Eq. (5), this implies that $\left(R_{t}-R_{t+1}\right)=\mu$ and (13) becomes,

$$
\delta \mu<(1-\delta) \Gamma
$$

The benefit from having a fixed exchange rate $(\Gamma)$ must be large relative to the inevitable reserve losses due to expanding domestic credit $(\mu)$. This condition must hold for the choice of a fixed exchange rate to have been optimal, and will therefore be assumed.

\subsection{The speculators' problem}

The solution to the speculators' problem is still described by uncovered interest parity, (2). However, speculators will be aware that the policy maker may decide to allow the exchange rate to float before reserves fall to $\bar{R}$. If it decides to do this the floating exchange rate will no longer be described by (9). To describe the shadow floating exchange rate let $\tilde{S}_{\tau, t}$ denote the exchange rate that would prevail at $t$ if the exchange rate was first floated in $\tau$. So the first subscript gives the date the fixed exchange rate was abandoned and the second subscript refers to the current date. Notice that the interpretation of that shadow floating exchange rate in the optimizing model is slightly different than it is in the myopic model. In the myopic model $\tilde{S}_{t}$ is the exchange rate that will prevail if there is a speculative attack. In the optimizing model $\tilde{S}_{t, t}$ is the exchange rate that will prevail if the 
policy maker abandons the fixed exchange rate. The difference arises because here the policy maker may choose to abandon the fixed exchange rate without a speculative attack.

Since all foreign currency transactions in the floating rate period take place in private markets, the money supply will be $R_{\tau}+D_{t}$ and Eqs. (1)-(5) yield

$$
\left[\left(\alpha-\beta i^{*}\right)+\beta\right] \tilde{S}_{\tau, t}=\left[R_{\tau}+D_{t}\right]+\beta E_{t}\left[\tilde{S}_{\tau, t+1}\right] .
$$

Assuming no speculative bubbles in the floating rate period, this difference equation implies that the shadow floating exchange rate can be expressed as,

$$
\tilde{S}_{\tau, t}=\frac{R_{\tau}+D_{t}}{\left(\alpha-\beta i^{*}\right)}+\frac{\beta \mu}{\left(\alpha-\beta i^{*}\right)^{2}} .
$$

If speculators were not holding very much foreign currency at the time of the abandonment, then the money supply will be relatively high, resulting in a high path for the floating exchange rate. Thus if reserves are high at the time of the move to a floating exchange rate then the exchange rate itself will be relatively high as well. In fact, if speculators did not expect a change in the fixed exchange rate, reserves would be given by Eq. (6) and the shadow floating exchange rate would be strictly greater than the fixed rate,

$$
\left\{\tilde{S}_{t, t} \mid E\left(q_{t}\right)=0\right\}=\bar{S}+\frac{\beta \mu}{\left(\alpha-\beta i^{*}\right)^{2}}
$$

where $q_{t}$ is the probability that the policy maker abandons the fixed exchange rate.

Proposition 1. In equilibrium, high probabilities of abandonment will result in low levels of reserves.

Proof. In the fixed exchange rate regime, uncovered interest parity, (2), can be written

$$
i_{t}=i^{*}+q_{t}\left[\left(\tilde{S}_{t, t+1} / \bar{S}\right)-1\right]
$$

which combined with (1), (3), (4), (5) and (16) and solving for $R_{t}$ yields

$$
R_{t}=\left(\alpha-\beta i^{*}\right) \bar{S}-\left[\frac{\left(\alpha-\beta i^{*}\right)+\beta}{\left(\alpha-\beta i^{*}\right)+\beta q_{t}}\right]\left[\frac{\beta \mu q_{t}}{\left(\alpha-\beta i^{*}\right)}\right]-D_{t}
$$

and hence

$$
\frac{\partial R_{t}}{\partial q_{t}}=\frac{-\beta \mu\left[\left(\alpha-\beta i^{*}\right)+\beta\right]}{\left[\left(\alpha-\beta i^{*}\right)+\beta q_{t}\right]^{2}}<0
$$

which completes the proof of Proposition 1. 
In equilibrium, the higher probabilities of abandonment will cause speculators to hold more foreign currency for speculative purposes, and hence lower central bank reserves. From (16) this implies that higher probabilities of abandonment will result in lower shadow floating exchange rates.

Proposition 2. If $q_{t}<1$ then $S_{t, t}>\bar{S}$. If $q_{t}=1$ then $S_{t, t}=\bar{S}$.

Proof. If $q_{t}=1$ Eq. (19) implies,

$$
R_{t}+D_{t}=\left(\alpha-\beta i^{*}\right) \bar{S}-\left[\frac{\beta \mu}{\left(\alpha-\beta i^{*}\right)}\right] \text {. }
$$

From this (16) yields the second part of the proposition. Since the shadow floating exchange rate is increasing in the level of reserves and the level of reserves is decreasing in $q_{t}$ by (20) the first part of the proposition follows, which completes the proof of Proposition 2.

Intuitively, if speculators are certain that the exchange rate will be abandoned they will continue to buy foreign currency as long as the shadow floating exchange rate exceeds the fixed rate. These foreign currency purchases decrease the money supply and hence decrease the shadow floating exchange rate until it equals the fixed rate. Put another way, the shadow floating exchange rate will always be at least as high as the fixed rate since otherwise speculators would find it profitable to sell foreign currency, thereby increasing the money supply and raising the shadow floating exchange rate.

Although the shadow floating exchange rate is always at least as high as the fixed rate, this will not induce an immediate speculative attack as it would in the traditional model. This is because here the shadow floating exchange rate is the rate that will prevail if the policy maker abandons the fixed exchange rate, not the rate that will prevail if there is a speculative attack. If speculators attack the fixed exchange rate and force its abandonment, they will decrease the money supply to the point where the shadow floating exchange rate is less than the fixed rate. Thus, although the floating exchange rate may exceed the fixed rate, this alone will not present speculators with a one sided bet unless the policy maker is expected to abandon the fixed exchange rate regime.

\subsection{Equilibrium}

In the standard model where the policy maker remains passive, speculators attack the fixed exchange rate as soon as the shadow floating exchange rate rises to the fixed rate. However, this attack imposes losses on the central bank, making it attractive to abandon the fixed rate just before the attack. By abandoning the fixed exchange rate regime one period early the policy maker would avoid the 
speculative attack at the cost of one less period of fixed exchange rates. One might presume that this would be an equilibrium, since in the traditional model with a myopic policy maker, the shadow floating exchange rate does not rise to the fixed rate until one period later. However, this is not the case. If the policy maker chooses to abandon the fixed exchange rate when reserves are still above $\bar{R}$ then the shadow floating exchange rate will be correspondingly higher and speculators will find it profitable to stage an attack in the beginning of that period.

Proposition 3. If $q_{t-1}=0$ and $q_{t}=1$ for any $t \leq \bar{T}$, then $R_{t-1}-R_{t}=\mu+\mu \beta$ / $(\alpha-\beta i *)$.

Proof. Trivial application of (19).

Recall that reserves fall by $\mu$ each period just due to expanding domestic credit. Therefore the implication of Proposition 3 is that if the policy maker adopts a pure strategy of abandoning with certainty at some time $t \leq \bar{T}$ and not before, there will be a speculative attack of size $\mu \beta /\left(\alpha-\beta i^{*}\right)$ as speculators attempt to exploit this deterministic strategy. Note that the size of the speculative attack is the same as the size of the attack in the myopic case and it does not depend on the date of the abandonment. As is well known, in the myopic model the size of the attack does not depend on the critical level of reserves $\bar{R}$, but the date of the speculative attack is uniquely determined by $\bar{R}$. Thus in the myopic model there is a one-to-one correspondence between $\bar{R}$ and the date of abandonment, given either, one can deduce the other. In Proposition 3 the specification of the date of abandonment $\left(q_{t-1}=0\right.$ and $\left.q_{t}=1\right)$ is therefore tantamount to picking a different critical level of reserves in the myopic model.

Proposition 4. In equilibrium $q_{t}<1$ for all $t<\bar{T}$.

Proof. By contradiction. Consider a $t<\bar{T}$ where $q_{t}=1$. It must be an optimal choice for the policy maker to abandon the fixed rate system, which from (11) implies,

$$
\frac{\left(R_{t}-\Gamma\right)}{(1-\delta)} \geq R_{t}+\frac{\delta\left(R_{t+1}-\Gamma\right)}{(1-\delta)}
$$

since $E_{t}\left(V_{t+1}\right) \geq\left(R_{t+1}-\Gamma\right) /(1-\delta)$ from inspection of (11). This inequality reduces to

$$
\delta\left(R_{t}-R_{t+1}\right) \geq(1-\delta) \Gamma .
$$

Speculators must be behaving optimally as well. Since $q_{t}=1$, Proposition 2 implies that speculators purchase foreign currency up to the point where $\tilde{S}_{t, t}=\bar{S}$. This yields, 


$$
R_{t}+D_{t}=\left(\alpha-\beta i^{*}\right) \bar{S}-\left[\beta \mu /\left(\alpha-\beta i^{*}\right)\right]
$$

and speculation in $t+1$ will only continue as long as the shadow floating exchange rate is at least as high as the fixed rate, $\tilde{S}_{t+1, t+1} \geq \bar{S}$, an inequality since $q_{t+1}$ may be less than one. This implies

$$
R_{t+1}+D_{t+1} \geq\left(\alpha-\beta i^{*}\right) \bar{S}-\left[\beta \mu /\left(\alpha-\beta i^{*}\right)\right] .
$$

Therefore optimal behavior for speculators implies

$$
R_{t}-R_{t+1} \leq D_{t+1}-D_{t}=\mu .
$$

So in equilibrium both (23) and (26) must hold which implies $\delta \mu \geq(1-\delta) \Gamma$. This contradicts (14), so $q_{t}=1$ cannot be an equilibrium which completes the proof of Proposition 4.

Intuitively, if the policy maker plans to abandon the fixed exchange rate, speculators will try to take advantage of this by purchasing foreign currency, resulting in low central bank reserves. So when the time comes for the policy maker to actually implement the switch to the floating rate, it will find that reserves are already quite low. The damage from speculators has already been done. The additional damage that they might do if the policy maker waits one more period is relatively small. So it is in the policy maker's best interest to continue maintaining the fixed exchange rate. Switching exchange rate regimes at time $t<\bar{T}$ with certainty cannot be part of an equilibrium strategy. The implication of this is that in equilibrium the policy maker will not be able to preemptively abandon the fixed rate with certainty at $t$ in order to avoid a speculative attack in $t+1$.

The argument given in the myopic case implies that $q_{t}=1$ for all $t \geq \bar{T}$. Therefore an implication of Proposition 4 is that the only remaining potential pure-strategy for the policy maker involves setting $q_{t}=0$ for all $t<\bar{T}$ and $q_{t}=1$ for all $t \geq \bar{T}$. Consider then what is necessary for this to be an equilibrium.

Proposition 5. If $t<\bar{T}$ and $q_{t+1}>0$ then $q_{t}=0$ can only be part of an equilibrium strategy if $R_{t}-R_{t+1} \leq(1-\delta) \Gamma / \delta$.

Proof. For the choice of $q_{t}=0$ to be optimal for the policy maker it must be that

$$
\frac{\left(R_{t}-\Gamma\right)}{(1-\delta)} \leq R_{t}+\frac{\delta\left(R_{t+1}-\Gamma\right)}{(1-\delta)}
$$

which reduces to

$$
R_{t}-R_{t+1} \leq(1-\delta) \Gamma / \delta
$$

Maintaining the fixed exchange rate will be optimal as long as in the next period 
reserves will not fall by more than $(1-\delta) \Gamma / \delta$, which completes the proof of Proposition 5.

Passively waiting for an expected drop in reserves can only be optimal for the policy maker if that drop is small relative to the policy maker's preference for fixed exchange rates. The value of having fixed exchange rates for one more period must be large enough to make enduring the loss worthwhile.

Proposition 6. With short period lengths no pure-strategy subgame-perfect Nash equilibrium exists.

Proof. From Proposition 4 and the argument made in the myopic case, the only potential pure-strategy remaining for the policy maker involves $q_{\bar{T}-1}=0$ and $q_{\bar{T}}=1$. By Proposition 3 this would imply that there would be a speculative attack in $\bar{T}, R_{\bar{T}-1}-R_{\bar{T}}=\mu+\mu \beta /\left(\alpha-\beta i^{*}\right)$. So from Proposition 5 if $\mu+\mu \beta /(\alpha-$ $\left.\beta i^{*}\right) \leq(1-\delta) \Gamma / \delta$ this will be an equilibrium. If the expected attack is very small relative to the policy maker's preference for fixed exchange rates, then it can be optimal to deliberately accept the attack rather than to give up even one period of the fixed exchange rate regime. In this case $q_{\bar{T}-1}=0$ can be part of an equilibrium strategy. However, this equilibrium is an artifact of the period length. If we consider short periods, this equilibrium cannot exist (see Appendix A). In particular, as we approach continuous time by taking the limit of the discrete time models as the period length goes to zero, then this equilibrium with passive acceptance of the speculative attack is not possible for any set of parameter values. The size and cost of the speculative attack is not dependent on the period length, but the opportunity cost of abandoning the fixed exchange rate system one period earlier is. With short enough periods the opportunity cost is negligible. Therefore if we consider short periods it will not be optimal for the policy maker to remain passive in the face of a predictable speculative attack. Hence $q_{\bar{T}-1}$ will not be zero in equilibrium. Thus from Proposition $4, q_{\bar{T}-1} \in(0,1)$ which completes the proof of Proposition 6.

Intuitively, if the policy maker can predict an oncoming speculative attack then it will wish to abandon the fixed exchange rate regime just before the attack. Likewise, if speculators can predict this preemptive abandonment of the fixed exchange rate regime, then they will exploit this knowledge by buying foreign currency just before the abandonment. Thus in order to avoid a speculative attack the policy maker must introduce uncertainty into the decisions of speculators. It cannot follow a predictable pure strategy, since such a strategy would result in a speculative attack.

The subgame-perfect Nash equilibrium can be constructed by backward induction. The argument made in the myopic case implies that in any equilibrium $q_{\bar{T}}=1$. Given this, it is possible to examine the policy maker's optimal strategy in 
$\bar{T}-1$. And from this it is possible to examine the policy maker's optimal strategy in $\bar{T}-2$, and so on.

Consider a time $t<\bar{T}$ where $q_{t+1}>0$. That is, in the coming period there will be a positive probability that the policy maker will abandon the fixed exchange rate. The policy maker must find this optimal in period $t+1$, which implies that it either strictly prefers to abandon the fixed rate regime in $t+1$ or it is indifferent between abandoning and maintaining the fixed exchange rate. In either case, from Eq. (11) the maximized expected present value of its objective function is given by $V_{t+1}=\left(R_{t+1}-\Gamma\right) /(1-\delta)$.

From Proposition $4, q_{t}=1$ is not possible. Suppose for a moment that $q_{t} \in(0$, 1 ), which means that the policy maker must be indifferent between maintaining and abandoning the fixed exchange rate regime. From (11) central bank reserves must be equal to

$$
R_{t}=R_{t+1}+(1-\delta) \Gamma / \delta
$$

On the other hand, if $q_{t}=0$ then reserves are given by (6), as can be seen from Eq. (19). This can be part of an equilibrium only if it implies $R_{t} \leq R_{t+1}+(1-\delta) \Gamma / \delta$ by Proposition 5 .

Thus, working backward from $\bar{T}-1$, it is possible to establish $\underline{T}$, the earliest state where abandonment of the fixed exchange rate can be an equilibrium outcome. Iterating (29) yields

$$
R_{t}=\bar{R}+(\bar{T}-t)(1-\delta) \Gamma / \delta .
$$

Eq. (30) describes the equilibrium level of reserves as long as it yields reserves that are less than those given by Eq. (6). At that point and earlier $q_{t}=0$ is an equilibrium and so reserves will follow (6). The path of reserves can be seen in Fig. 2. After $\underline{T}$ reserves decline quickly, but continuously, until they reach their lower bound at $\bar{T}$.

Consider the problem of an individual speculator. Suppose that, at the moment, reserves are high and that in the next period they will be relatively low. The speculator therefore realizes that the policy maker will prefer to abandon the fixed rate regime this period rather than permit such a large drop in reserves. So he will purchase foreign currency in this period. This means that the drop in foreign currency reserves will not be as dramatic in the coming period. Therefore, the policy maker will no longer be quite as eager to abandon the fixed rate.

Each speculator will purchase foreign currency as long as the policy maker prefers to abandon the fixed rate. When it is indifferent between abandoning and maintaining the fixed rate, they will realize that if they purchase additional foreign currency the drop in reserves between the current period and the next will be small enough so that the policy maker will prefer not to abandon. Since speculation decreases the money supply, it raises the domestic interest rate above the foreign 


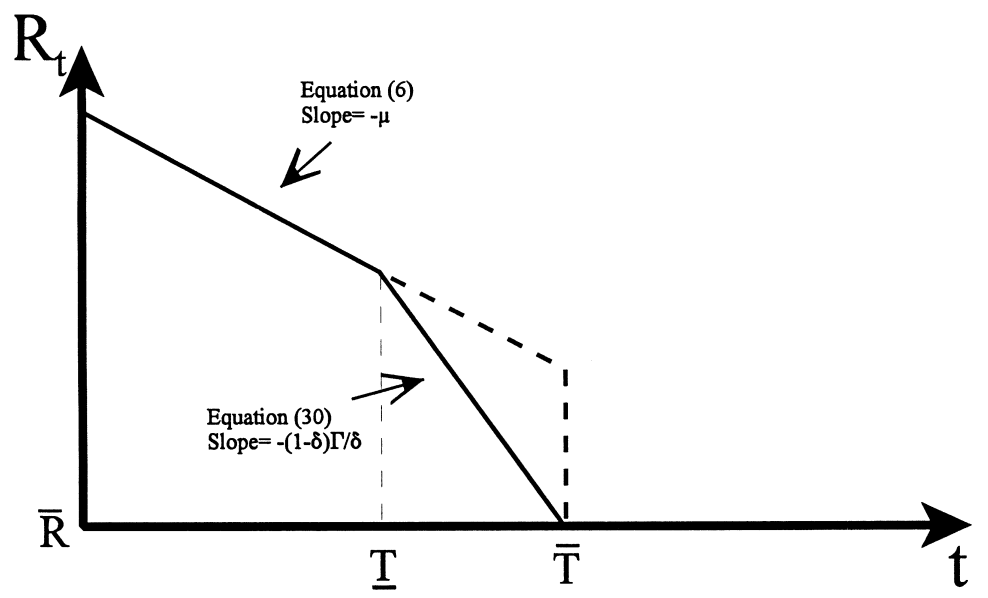

Fig. 2. Reserves with an optimizing policy maker.

rate. Hence purchasing foreign currency entails an opportunity cost and they will not purchase additional foreign currency.

So optimizing behavior on the part of speculators ensures that reserves are at a level where the policy maker either strictly prefers maintaining the fixed exchange rate one more period or is indifferent between abandoning and maintaining the fixed rate. In other words, optimizing speculators will always ensure that the policy maker does not strictly prefer to abandon the fixed exchange rate regime. If it did so, speculators could make profits by purchasing additional foreign currency, making abandonment less attractive to the policy maker. Since sudden attacks on foreign currency reserves make preemptive abandonment of the fixed exchange rate attractive, in equilibrium there can be no such predictable attacks.

Since this point is important, it is worth emphasizing with a counter example. Suppose that there was a predictable speculative attack, defined as a predictable, sudden, large drop in reserves. Then just before the drop the policy maker would abandon the fixed exchange rate system, thereby avoiding the attack. If it was planning on doing so, however, speculators would buy foreign currency just before it did. But this would imply that foreign currency reserves would already be low by the time of the expected attack, so the drop in reserves would be relatively small. The same logic applies to the period before, and the period before that. Therefore, in equilibrium there cannot be a predictable speculative attack.

In the range $t<\underline{T}$ the policy maker prefers to continue maintaining the fixed exchange rate so reserves decline one for one with the expansion of domestic credit. In the period $t \in[\underline{T}, \bar{T})$ speculation ensures that the policy maker is indifferent between abandoning and maintaining the fixed rate regime, which implies that reserves are declining at a greater rate.

From this information on the path of reserves it is straightforward to determine 
the behavior of other variables. Firstly the behavior of all the endogenous variables will be derived and then the intuition for the results will be discussed. During the period $t<\underline{T}$ there is no chance that the fixed exchange rate will be abandoned $\left(q_{t}=0\right)$. This implies that $i_{t}=i^{*}$ and that the shadow floating exchange rate is given by Eq. (17). After $\underline{T}$ reserves are given by Eq. (30) and domestic credit can always be written as $D_{t}=D_{\bar{T}}+(t-\bar{T}) \mu$. The shadow floating exchange rate can be found by substituting these into (16),

$$
\tilde{S}_{t, t}=\left[\frac{\bar{R}+D_{\bar{T}}}{\left(\alpha-\beta i^{*}\right)}+\frac{\beta \mu}{\left(\alpha-\beta i^{*}\right)^{2}}\right]+(t-\bar{T}) \frac{\mu-(1-\delta) \Gamma / \delta}{\left(\alpha-\beta i^{*}\right)} .
$$

The bracketed term is equal to the fixed exchange rate by (10) so the shadow floating exchange rate is simply

$$
\tilde{S}_{t, t}=\bar{S}+(t-\bar{T}) \frac{\mu-(1-\delta) \Gamma / \delta}{\left(\alpha-\beta i^{*}\right)} .
$$

From this, (5), (10), and the fact that $\underline{T}$ is defined as the time where (6) and (30) yield the same level of reserves, it is straightforward to show that at $\underline{T}$ the shadow floating exchange rate is $\tilde{S}_{\underline{T}, \underline{T}}=\bar{S}+\beta \mu /\left(\alpha-\beta i^{*}\right)^{2}$, which is equal to (17). So the shadow floating exchange rate is constant and above the fixed rate before $\underline{T}$. Then it declines linearly, reaching the fixed exchange rate at $\bar{T}$.

To examine the behavior of the interest rate in equilibrium note that (1), (3) and (4) must hold yielding,

$$
i_{t}=\alpha / \beta-\left(R_{t}+D_{t}\right) / \beta \bar{S}
$$

and during $t \in[\underline{T}, \bar{T}]$ reserves are given by Eq. (30) so this can be expressed as,

$$
i_{t}=\frac{\alpha}{\beta}-\frac{\left(\bar{R}+D_{\bar{T}}\right)}{\beta \bar{S}}+(\bar{T}-t)\left[\frac{\mu-(1-\delta) \Gamma / \delta}{\beta \bar{S}}\right] .
$$

Using Eq. (10) this can be reduced to

$$
i_{t}=i^{*}+\frac{\mu}{\left(\alpha-\beta i^{*}\right) \bar{S}}+(\bar{T}-t)\left[\frac{\mu-(1-\delta) \Gamma / \delta}{\beta \bar{S}}\right] .
$$

From the definition of $\underline{T}$ the interest rate is equal to the world rate at $\underline{T}$. It then increases linearly until it reaches $i^{*}+\mu /\left(\alpha-\beta i^{*}\right) \bar{S}$ at $\bar{T}$.

The one remaining endogenous variable is $q_{t}$, the probability that the policy maker abandons the fixed exchange regime. This can be derived by noting that since $\tilde{S}_{t, t+1}=\tilde{S}_{t, t}+\mu /\left(\alpha-\beta i^{*}\right)$, Eq. (32) and uncovered interest parity (18) yield,

$$
q_{t}=\frac{\left(\alpha-\beta i^{*}\right) \bar{S}\left(i_{t}-i^{*}\right)}{\mu+(t-\bar{T})[\mu-(1-\delta) \Gamma / \delta]} .
$$

At $\underline{T}, i_{t}=i^{*}$, so Eq. (36) says that the probability of abandoning the fixed 
exchange rate is zero at $\underline{T}$. It then increases, at an increasing rate, until it reaches 1 at $\bar{T}$.

It is also worth noting that if we made the additional assumptions of risk neutrality and perfectly competitive forward markets, the one period ahead forward exchange rate, $F_{t}$, would be equal to the expected exchange rate in the next period

$$
F_{t}=q_{t} \tilde{S}_{t, t+1}+\left(1-q_{t}\right) \bar{S}
$$

Combining this with Eq. (18) yields,

$$
F_{t}=\left[1+\left(i_{t}-i^{*}\right)\right]
$$

Let $f_{t}$ denote the one period ahead forward exchange rate premium, defined as

$$
f_{t} \equiv \frac{\left(F_{t}-\bar{S}\right)}{\bar{S}}=\left(i_{t}-i^{*}\right)
$$

So the forward exchange rate premium is equal to the interest rate differential, starting at zero at $\underline{T}$ and rising linearly to $\mu /\left(\alpha-\beta i^{*}\right) \bar{S}$ at $\bar{T}$.

\subsection{Interpretation}

These results are summarized in Fig. 3. Before $\underline{T}$ there is no chance of the policy maker abandoning the fixed exchange rate regime. Since $\bar{T}$ is far in the future, the policy maker wants to maintain the fixed rate. Reserves are high enough so that if speculators attacked and drove reserves to $\bar{R}$, forcing a move to a floating exchange rate, they would contract the money supply to a point where the fixed exchange rate would exceed the floating rate; hence they do not attack. The domestic interest rate is therefore equal to the world rate.

After $\underline{T}$ this situation changes. Both speculators and the policy maker realize that $\bar{T}$ is approaching and that the fixed exchange rate must be abandoned. This gives the policy maker an incentive to abandon it before speculation drives down foreign currency reserves. But speculators are aware of this incentive and purchase foreign currency in anticipation of the potential jump in exchange rates. As time goes by, speculators purchase more foreign currency, always keeping the policy maker indifferent between maintaining and abandoning the fixed exchange rate regime. This drives up the domestic interest rate and forward exchange rate premium while driving down the shadow floating exchange rate. Therefore the opportunity cost of holding foreign currency is increasing, and the benefit to successful speculation is declining. But the probability that speculation will be successful is increasing rapidly, ensuring that the expected return from holding foreign currency remains constant at zero. However, in the event of a move to floating exchange rates, while there is no sudden drop in central bank reserves, the 


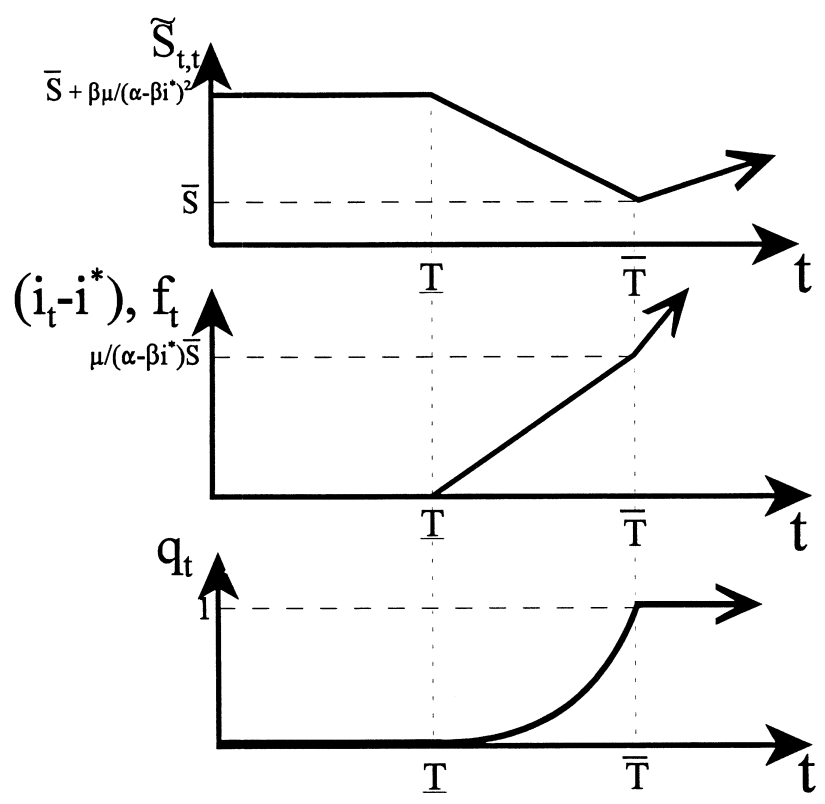

Fig. 3. The evolution of the shadow floating exchange rate, the interest rate differential and forward exchange rate premium, and the probability of a move to a floating exchange rate regime.

ex post profits from holding foreign currency can be substantial, since the shadow floating exchange rate is above the fixed rate until $\bar{T}$.

\section{Conclusion}

A version of the Krugman (1979) balance-of-payments crisis model is developed that explicitly incorporates a rational, forward-looking policy maker. The original feature of the model is that the cost of a speculative attack to the policy maker does not vanish as the duration of the attack goes to zero. This permits an

\footnotetext{
${ }^{14}$ The period after $\bar{T}$ is also depicted in Fig. 3. This is the behavior of the variables off the equilibrium path. These states will never be reached, the abandonment of the fixed exchange rate regime will occur with certainty at or before $\bar{T}$. However, to derive the equilibrium strategies it is necessary to specify the alternative, what would happen if the optimal strategies were not implemented. This is what is given to the right of $\bar{T}$. These strategies are precisely the off-equilibrium strategies which are implicit in the traditional analysis of the model. If the fixed exchange rate is still maintained after $\bar{T}$, then speculators will immediately attack the central bank's foreign currency reserves forcing the abandonment of the fixed exchange rate. Therefore $R_{t}=\bar{R}$ and $q_{t}=1$. This implies that the shadow floating exchange rate and the interest rate are given by (9) and (2), respectively, which is what is depicted in this part of Fig. 3, but these states will never be observed since the fixed exchange rate will always be abandoned before they are reached.
} 
analysis of strategic interaction between the policy maker and speculators in the context of predictably deteriorating fundamentals. In this model the policy maker is able to choose the timing of the move to floating exchange rates while speculators attempt to predict this date and exploit it through their foreign currency purchases. It is shown that the policy maker has an incentive to introduce uncertainty into the decisions of speculators. By doing so it is possible for the policy maker to avoid predictable speculative attacks. This is true even when the only policy instrument available to the policy maker is the decision to abandon or continue maintaining the fixed exchange rate regime. When policy makers have more sophisticated policy instruments at their disposal, avoiding predictable attacks is even easier. Thus, the hypothesis of predictable speculative attacks is inconsistent with rational, forward-looking behavior on the part of the policy maker.

The existence of speculators causes the central bank to abandon the fixed exchange rate much earlier than it would have in their absence. This is true in equilibrium even though there are no speculative attacks. With capital mobility and an optimizing policy maker it is the threat of such attacks that causes the policy maker to abandon the fixed exchange rate. ${ }^{15}$ Even when we do not observe significant speculation, the presence of speculators can have an important effect on the decisions of the monetary authority. In fact, the earliest abandonments of fixed exchange rates will be accompanied by low speculation. But these abandonments are the ones whose timings have been most affected by the presence of speculators.

There is an important element of time inconsistency here. Rather than enduring the protracted period of increasing speculation that it must face in equilibrium, the policy maker would prefer the equilibrium of the myopic model. In the myopic model the policy maker had relatively high reserves right up to the attack. While the speculative attack is costly for the policy maker, it is not as costly as the protracted period of increasing speculation. ${ }^{16}$ The policy maker would like to convince speculators that it will not abandon the fixed exchange rate unless reserves are driven down so far that continued maintenance is impossible. While it would like to be able to commit to this policy, in practice it cannot. Speculators know that the policy maker has an incentive to abandon the fixed exchange rate policy just before they are expected to attack. The policy maker's announced policy is not credible, and so in equilibrium it must endure a protracted period of increasing speculation.

In practice, central banks almost universally claim that they will never, under

\footnotetext{
${ }^{15}$ This was almost certainly a major factor in the 1999 Brazilian abandonment, for example.

${ }^{16}$ This can be seen by realizing that in equilibrium the policy maker is indifferent between abandoning the fixed exchange rate anywhere during this period. In particular, it is willing to wait until it is forced to abandon. At that point the present value of its payoff is the same as it would be if there had been an attack. But on the path to that point the forward-looking policy maker endured increasing speculative pressure, while the myopic policy maker did not.
} 
any circumstances, abandon fixed exchange rate regimes. They are, in effect, claiming to be myopic. In equilibrium it is, in fact, preferable to be myopic, but it is not credible. In the absence of a device which irrevocably commits the central bank to the policy, rational speculators will not believe these claims. It should be noted that this is not an argument in favor of currency boards, in spite of the fact that currency boards cannot legally abandon fixed exchange rate regimes. Since any government with the power to institute a currency board also has the power to abolish it, currency boards do not solve the time inconsistency problem. They simply transfer the problem from the central bank to the government.

With a forward-looking monetary authority, there is an incentive to introduce uncertainty into the decisions of speculators. If speculators are certain of the conditions that will cause the policy maker to abandon the fixed exchange rate regime, they will engage in a sudden speculative attack just before the abandonment. In order to avoid such attacks the policy maker must ensure that speculators are not certain of what it will do. This endogenous uncertainty implies that the timing of the move to a floating exchange rate cannot be known with certainty, even in a completely non-stochastic structure. Fundamentals move deterministically but the outcome is stochastic. However, while the date of the abandonment of the fixed exchange rate regime cannot be known with certainty, fundamentals confine the abandonment to a bounded set of dates. The variables that determined the attack date in the traditional analysis also help determine the possible dates of a breakdown with an optimizing policy maker. Thus the model is consistent with the wealth of empirical evidence found using the traditional approach. Moreover, with an optimizing policy maker the probability of abandonment at each date can be completely specified.

This derived expression for the probability of abandoning the fixed exchange rate is remarkably similar to that assumed by Cumby and van Wijnbergen in their 1989 empirical work on Argentina's crawling peg. In order to capture the idea that changing the exchange rate regime is a policy decision they assume that the conditional p.d.f. of the level of reserves at the time of abandonment is distributed uniformly. This assumption implies that the probability of abandonment evolves quite similarly to Eq. (36). ${ }^{17}$ Hence it is possible to think of this paper as a theoretical foundation for their earlier empirical work, or, conversely, their empirical work as an ex ante empirical application of this type of model. ${ }^{18}$

The implication of this endogenous probability of abandonment is that the time

\footnotetext{
${ }^{17}$ Abstracting from their rich stochastic structure, Cumby and van Wijnbergen's assumption implies $q_{t}=1 /(1+(\bar{T}-t))$ in the notation of this paper. Eq. (36) can be rewritten as $q_{t}=\left[k_{1} /\left(k_{2}+k_{3}(\bar{T}-\right.\right.$ $t)$ ) $-k_{4}$ where the $k_{i} \mathrm{~s}$ are positive functions of parameters. These expressions for the probability of abandoning the fixed exchange rate system are quite similar and evolve in much the same way but there is no set of parameters in this model which would make them identical, $k_{1}=k_{2}=k_{3}=1$ is not possible. Nevertheless, Cumby and van Wijnbergen's estimation method can be easily extended to use related specifications of the probability of abandonment.

${ }^{18}$ Guidotti and Végh (1999) also assume a very similar specification of the probability of abandonment in their theoretical work.
} 
near an abandonment of a fixed exchange rate is likely to be characterized by a high degree of uncertainty. This uncertainty is not an exogenous feature of fixed exchange rates but rather is introduced endogenously and deliberately by the policy maker in an attempt to move to a floating exchange rate regime before a speculative attack.

The seminal work of Harsanyi (1973) provides an additional interpretation of this endogenous uncertainty. If speculators were unsure of the objective function being used by the policy maker, or about the current level of reserves, then the policy maker would use a pure strategy. However, equilibrium uncertainty would be present due to this exogenous uncertainty about the policy maker's objective function. Harsanyi's insight is that as this exogenous uncertainty goes to zero, the equilibrium uncertainty does not. In fact, the probability of abandoning the fixed exchange rate at each time approaches the probabilities found in the model. This remarkable fact implies that even arbitrarily small uncertainty about the policy maker's objective function or foreign currency reserves will lead to very large uncertainty about the conditions under which the policy maker will abandon the fixed exchange rate regime. Hence, it is not realistic to presume that if speculators have reasonably good information about the policy maker's objective function and about central bank foreign currency holdings, that they will be able to deduce good estimates of the conditions under which the policy maker will abandon the fixed exchange rate regime.

This endogenous uncertainty means that prior to the switch in exchange rate regimes there are increasing domestic interest rates, and increasing forward exchange rate premia over the fixed exchange rate. In addition, the exchange rate may jump during the move to the floating rate, yielding ex post profits to foreign currency speculators. These empirical implications are attractive features of this model that have previously been generated in the traditional model by incorporating uncertainty via exogenous shocks. However, the magnitude of the uncertainty introduced to the fixed exchange rate period relative to the flexible rate period is different in each approach, which leads to differences in the magnitude of the empirical implications. These empirical implications of this paper which are different from those generated by the exogenous shock approach include the following.

- Interest differentials leading up to the breakdown in the fixed exchange rate are greater than the interest differentials in the flexible exchange rate period.

- The forward exchange rate premium leading up to the breakdown in the fixed exchange rate is greater than the forward exchange rate premium in the flexible exchange rate period.

- The size of the devaluation at the breakdown in the fixed exchange rate is not dependent on the size of the last shock.

The exogenous shock approach implies that the length of the period of 
increasing interest rates and forward exchange rate premia is related to the size of the expected shocks. The size of a jump in the exchange rate is directly related to the size of the last shock. In fact the magnitude of the jump must be less than the jump that would occur if the same shock hit in a flexible exchange rate environment. Likewise the interest differentials and forward premia must be less than what they would have been in a flexible exchange rate environment. With an optimizing policy maker, however, these empirically observed phenomena are no longer the result of exogenous shocks. They arise in equilibrium even in this non-stochastic framework due to the endogenous uncertainty introduced by the policy maker. This endogenous uncertainly is confined to the period leading up to the breakdown in the fixed exchange rate regime and hence is greater than the uncertainty in the flexible exchange rate period.

The results are encouraging for the viability of temporary nominal anchor policies to combat runaway expectations-driven inflation. These implications are more speculative, but nevertheless worth considering. By introducing uncertainty into speculators' decisions, it is in fact possible for a central bank to leave a fixed exchange rate regime gracefully, even when the abandonment is anticipated by rational speculators. Nevertheless, the results of the model also suggest that these policies are likely to be very dangerous. During the time leading up to the abandonment of the fixed rate regime, the existence of rational speculators ensures that the policy maker is indifferent between maintaining and abandoning the fixed exchange rate. This means that the central bank will be very vulnerable to shifts in peoples' perceptions of its commitment to the announced policy. Any perceived weakness, or any negative shock could cause a sudden crash. ${ }^{19}$ Seen in this light, it is not surprising that while we do see several successful implementations of nominal anchor policies (most notably Poland and Israel), the list of dramatic failures is much longer. However, the reader should be aware that the model used here is very stylized and does not incorporate many of the features that are important to the success of nominal anchor policies. Work still needs to be done in more fully specified models to see how the policy maker's incentive to introduce uncertainty into speculators' decisions affects the adjustment of inflationary expectations, and how this incentive interacts with the possibility of rational and self-fulfilling expectations of attacks.

One significant implication of introducing an optimizing monetary authority is that it implies that speculative attacks cannot be precipitated by predictable movements in fundamentals. If speculative attacks were predictable, the policy maker would avoid them by abandoning the fixed exchange rate system just before

\footnotetext{
${ }^{19}$ See, for example, Obstfeld (1996) for a model where exogenous shocks can alter the central bank's tradeoff between fixed and floating exchange rates. Typically in models of this type the central bank is initially assumed to strictly prefer fixed exchange rates. Nevertheless, large enough negative shocks can decrease the attractiveness of fixed rates, and create the potential for a speculative attack. The danger would be even greater starting from a position of indifference between the two exchange rate regimes.
} 
they occurred. However, this would mean that the breakdown of the fixed rate regime was predictable and rational speculators would exploit this, resulting in an earlier attack. But the same logic would apply to that attack as well. Therefore, in equilibrium, speculative attacks cannot be predictable in a world with an optimizing policy maker. ${ }^{20}$ Speculative pressure, however, may be entirely predictable.

This does not imply that speculative attacks do not depend on fundamentals. Many models of speculative attacks with optimizing monetary authorities imply that the existence of multiple equilibria depends on fundamentals. See Cole and Kehoe (1996a,b), Davies and Vines (1995), Obstfeld (1994, 1996), Ozkan and Sutherland (1998), and Velasco (1997). The point is that while the conditions for a speculative attack may depend on predictable fundamentals, the precise time of a speculative attack cannot. By extension one could speculate that in models with multiple equilibria the coordination of speculator expectations on a particular equilibrium cannot depend on predictable variables, since otherwise the policy maker could predict the attack, and therefore avoid it. The coordination of speculator expectations could, however, depend on the unpredictable components of predictable variables, including the unpredictable components of fundamentals.

\section{Acknowledgements}

This paper is adapted from the fifth chapter of my 1996 Georgetown University Ph.D. dissertation which was completed while I was visiting the Division of International Finance at the Board of Governors of the Federal Reserve System. I would like to thank the members of the division for helpful discussion and for providing an outstanding research environment. I would also like to thank James Albrecht, Susan Collins, Behzad Diba, Robert Flood, Chul Park, Tuvana Pastine, Kenneth Rogoff, Andrew Rose, David Stockman and two anonymous referees for their comments and extraordinary assistance. Responsibility for errors remains my own.

\section{Appendix A}

To examine the possibility that the model might be able to generate Krugman style speculative attacks with a frequently optimizing policy maker, the analysis is

\footnotetext{
${ }^{20}$ Actually, this result does not depend on the monetary authority per se, but rather on speculators' perceptions of the monetary authority, since it is speculators who engage in speculative attacks and the strategy of the policy maker is not observable to them. In the model, rationality implies that perceptions are the same as reality. In the real world this may not necessarily be the case. However, as long as speculators perceive that the policy maker is behaving rationally, there cannot be predictable speculative attacks.
} 
extended to allow for an arbitrary period length, $n$. Low values of $n$ imply frequent decision making on the part of the policy maker and the preceding analysis is a special case where $n=1$. As $n \rightarrow 0$ the model approaches continuous time. ${ }^{21}$

Eqs. (1), (3) and (4) are not dependent on the period length and can be retained without modification, noting only that $i_{t}$ in the money demand Eq. (3) refers to the interest return over calendar time 1 . Therefore the per-period interest rate is given by $n i_{t}$, so Eq. (2) becomes,

$$
n i_{t}=n i^{*}+E_{t}\left[\left(S_{t+1} / S_{t}\right)-1\right]
$$

and (5) is,

$$
D_{t}=D_{t-1}+n \mu \text {. }
$$

From these equations the shadow floating exchange rate in the traditional model can be derived using the same method to show that (9) still holds. The time of the speculative attack in the traditional model $\bar{T}$ is given by $\tilde{S}_{t}=\bar{S}$ which implies that reserves fall by $\beta \mu /\left(\alpha-\beta i^{*}\right)$ at $\bar{T}$. So the size of the speculative attack in the traditional model is not dependent on the period length. This is unsurprising since the model generates attacks in continuous time as well. ${ }^{22}$

Now moving to the problem of the policy maker, the policy maker's per-period discount rate is $\delta^{n}$. Its per-period payoff is proportional to the period length: $n R_{t}$ with fixed exchange rates and $n\left(R_{t}-\Gamma\right)$ with floating rates. Therefore the policy maker's maximization problem is

$$
V_{t}=\max \left\{\left[\frac{n\left(R_{t}-\Gamma\right)}{1-\delta^{n}}\right],\left[n R_{t}+\delta^{n} E_{t}\left(V_{t+1}\right)\right]\right\} .
$$

We are interested here in whether it is optimal for the policy maker to set $q_{\bar{T}-1}=0$ knowing that there will be a speculative attack in the next period. If this is so, then from the maximization of (A.3),

$$
n\left(R_{\bar{T}-1}-\Gamma\right) /\left(1-\delta^{n}\right) \leq n R_{\bar{T}-1}+\delta^{n} V_{\bar{T}} .
$$

Since there will be a speculative attack in $\bar{T}$, reserves will fall to $\bar{R}$, and the fixed exchange rate will be abandoned. Therefore, $V_{\bar{T}}=n(\bar{R}-\Gamma) /\left(1-\delta^{n}\right)$. So in order for $q_{\bar{T}-1}=0$ to be an equilibrium it must be the case that,

$$
\frac{n\left(R_{\bar{T}-1}-\Gamma\right)}{\left(1-\delta^{n}\right)} \leq n R_{\bar{T}-1}+\frac{n \delta^{n}\left(R_{\bar{T}}-\Gamma\right)}{\left(1-\delta^{n}\right)}
$$

which reduces to

$$
R_{\bar{T}-1}-R_{\bar{T}} \leq\left(1-\delta^{n}\right) \Gamma / \delta^{n} .
$$

\footnotetext{
${ }^{21} \mathrm{~A}$ number of important issues arise at the transition between discreet and continuous time, see Simon and Stinchcombe (1989), but these issues do not affect the discussion here.

${ }^{22}$ The original Krugman (1979) model was cast in continuous time.
} 
Since reserves fall by $n \mu$ each period just due to expanding domestic credit and since there will be a speculative attack depleting reserves by $\beta \mu /\left(\alpha-\beta i^{*}\right)$ in period $\bar{T}, R_{\bar{T}-1}-R_{\bar{T}}=n \mu+\beta \mu /\left(\alpha-\beta i^{*}\right)$. Therefore (A.6) requires

$$
\mu \beta /\left(\alpha-\beta i^{*}\right) \leq\left(1-\delta^{n}\right) \Gamma / \delta^{n}-n \mu .
$$

This condition must hold for it to be optimal for the policy maker to remain passive in the face of an expected speculative attack. In the limit as $n \rightarrow 0$ the right-hand side goes to zero and the inequality cannot hold for any set of parameters. Therefore with short periods there cannot be an equilibrium where the policy maker remains passive in the face of a predictable speculative attack.

\section{References}

Agénor, P., Bhandari, J., Flood, R., 1992. Speculative attacks and models of balance-of-payments crises. International Monetary Fund Staff Papers 39, 357-394.

Andersen, T., 1994. Shocks and the viability of a fixed exchange rate commitment. CEPR, Discussion paper \#969.

Bénabou, R., 1989. Optimal price dynamics and speculation with a storable good. Econometrica 57, 41-80.

Blackburn, K., Sola, M., 1993. Speculative currency attacks and balance-of-payments crises. Journal of Economic Surveys 7, 119-144.

Cole, H., Kehoe, T., 1996a. A self-fulfilling model of Mexico's 1994-1995 debt crisis. Journal of International Economics 41, 309-330.

Cole, H., Kehoe, T., 1996b. Self-fulfilling debt crises. Federal Reserve Bank of Minneapolis Research Department, Staff report \#211.

Cumby, R., van Wijnbergen, S., 1989. Financial policy and speculative runs with a crawling peg: Argentina 1979-1981. Journal of International Economics 27, 111-127.

Davies, G., Vines, D., 1995. Equilibrium currency crises: are multiple equilibria self-fulfilling or history dependent. CEPR, Discussion paper \#1239.

Flood, R., Garber, P., 1984a. Gold monetization and gold discipline. Journal of Political Economy 92, 90-107.

Flood, R., Garber, P., 1984b. Collapsing exchange-rate regimes: some linear examples. Journal of International Economics 17, 1-13.

Flood, R., Garber, P., Kramer, C., 1996. Collapsing exchange rate regimes: another linear example. Journal of International Economics 41, 223-234.

Flood, R., Marion, N., 1999. Perspectives on the recent currency crisis literature. International Journal of Finance and Economics 4, 1-26.

Guidotti, P., Végh, C., 1999. Losing credibility: the stabilization blues. International Economic Review 40, 23-51.

Harsanyi, J., 1973. Games with randomly disturbed payoffs: a new rational for mixed-strategy equilibrium points. International Journal of Game Theory 2, 1-23.

Jeanne, O., 1997. Are currency crises self-fulfilling? A test. Journal of International Economics 43, 263-286.

Krugman, P., 1979. A model of balance-of-payments crises. Journal of Money, Credit, and Banking 11, 311-325.

Mas-Colell, A., Whinston, M., Green, J., 1995. Microeconomic Theory. Oxford University Press, Oxford. 
Morris, S., Shin, H., 1998. Unique equilibrium in a model of self-fulfilling currency attacks. American Economic Review 88, 587-597.

Obstfeld, M., 1986. Rational and self-fulfilling balance-of-payments crises. American Economic Review 76, 72-81.

Obstfeld, M., 1994. The logic of currency crises. NBER, Working paper \#4640.

Obstfeld, M., 1996. Models of currency crises with self-fulfilling features. CEPR, Discussion paper \#1315.

Ozkan, G., Sutherland, A., 1994. A model of the ERM crisis. CEPR, Discussion paper \#879.

Ozkan, G., Sutherland, A., 1995. Policy measures to avoid a currency crisis. Economic Journal 105, $510-519$

Ozkan, G., Sutherland, A., 1998. A currency crisis model with an optimising policymaker. Journal of International Economics 44, 339-364.

Pastine, I., 1996. A model of panic: excess demand and consumption smoothing during speculative attacks. Bilkent University, Mimeo.

Pastine, I., 2000. Devaluation of fixed exchange rates: optimal strategy in the presence of speculation. Economic Theory 15, 631-661.

Salant, S., Henderson, D., 1978. Market anticipations of government policies and the price of gold. Journal of Political Economy 86, 627-648.

Simon, L., Stinchcombe, M., 1989. Extensive form games in continuous time: pure strategies. Econometrica 57, 1171-1214.

Velasco, A., 1994. Are balance of payments crises rational? A dynamic game approach. New York University, C.V. Starr Center, Economic research report 94-08.

Velasco, A., 1997. When are fixed exchange rates really fixed? Journal of Development Economics 54, $5-25$. 